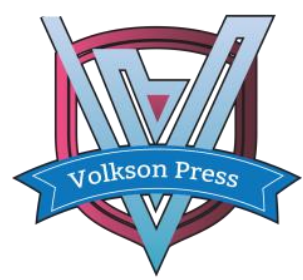

Contents List available at VOLKSON PRESS

Economics \& Management Innovations(EMI)

DOI : http://doi.org/10.26480/icemi.01.2017.353.355

\title{
How Anheuser-Busch InBev Improve Marketing Channel: A Case Study of Fujian Province in China
}

\author{
Shan Shan Wang', ${ }^{1,}$, Si Min Huang ${ }^{2}$ \\ Xiamen University of Technology, No.600 Ligong Road, Jimei District, Xiamen, 361024, Fujian Province, China \\ *wangshanshan@xmut.edu.cn
}

This is an open access article distributed under the Creative Commons Attribution License, which permits unrestricted use, distribution, and reproduction in any medium, provided the original work is properly cited.

\section{ARTICLE DETAILS}

\section{Article History:}

Received 02 october 2017 Accepted 06 october 2017 Available online 11 october 2017

Keywords:

marketing channel; beer; terminal; brand image.

\section{ABSTRACT}

Marketing channel, a key section and foundation of sales, can be improved by the continuous efforts of the enterprise. To investigate the detail measures of improving marketing channel, taking Anheuser-Busch InBev ( $\mathrm{AB}$ InBev) as the subject to analyze the statue quo of its market performance, and raise the problems including unsatisfactory segmentation in the sales channel, poor management of terminal channels, not close cooperation among offline channels, failure in constructing corporate image and so on. Finally corresponding suggestions to the problems existed are provided.

\section{The sale situation of beers in Fujian province}

\subsection{The status of beer market in Fujian province}

Competition in beer market of Fujian province, an important market in China, is particularly fierce. Differing from other brands receiving protection policies, the local brands compete with others fiercely. There are a great number of domestic brands, including China Resources, Harbin Beer, Tsingtao Beer, Yanjing Beer and many other imported brands under its advantages in foreign trade. In the first half of 2016, the amount of the imported beer reach 73 million litre, accounting for 24 percent of imported amount year-on-year. So the beer market here has turned whit-hot due to the fierce competition. Harbin, Budweiser and Sedrin are three major brands.

\subsection{The beer marketing channel in Fujian province}

The marketing channel of beer in Fujian province can be divided into three kinds: Firstly, the terminal of retail groceries. Supermarkets like Yonghui and Wal-mart and other unknown middle and small stores are an important marketing channel of beer. The second is dining and entertainment terminal. Usually, beer is taken as an extra for meal and its demand has become a major reason for customers' attendance, in KTV and other entertainment venues. Thirdly, the internet terminal. With the development of e-commerce, more and more products are available online. And customers prefer to shop online. All kinds of beer are available through internet

\section{Overview of AB InBev's marketing channels in Fujian province}

In the development of $\mathrm{AB}$ InBev's marketing channels, it is special that $\mathrm{AB}$ InBev has chosen short marketing channels for highly regulating marketing channels as much as possible, which helps AB InBev avoid the decline of company's control on account of too long marketing channels. For example, $A B$ InBev requires that its dealers only involve $A B$ InBev without the distribution of other brands, which cause the highly cooperation between $\mathrm{AB}$ InBev and its dealers, that is, $\mathrm{AB}$ InBev supports dealers more and dealers at the same time respond quicker with the aspects of various marketing channel construction requirements as well as strategy implementation. This kind of marketing channel is better for $\mathrm{AB}$ InBev because not only can it reduce costs and achieve a highly management of marketing channels but also it help strengthen the brand image of $\mathrm{AB}$ InBev.In addition, $\mathrm{AB}$ InBev also builds online marketing channels and you can find the flagship stores of both $A B$ InBev and
Budweiser on such major comprehensive e-commerce platforms as Tmall and Jingdong, where varieties of $\mathrm{AB}$ InBev's products are sold for consumers online. Though with the help of e-commerce platforms in the online marketing channels of this kind, this online marketing channel actually is a direct channel self-supported by AB InBev. It is from the copy writing, advertisement to customer service and so on that $A B \operatorname{InBev}$ is solely responsible for .

Table1 the sales income of $\mathrm{AB}$ InBev in Fujian province

unit:hundred million dollars

\begin{tabular}{|l|l|l|l|l|l|l|l|}
\hline & 2010 & 2011 & 2012 & 2013 & 2014 & 2015 & 2016 \\
\hline $\begin{array}{l}\text { the sales income } \\
\text { in Fujian }\end{array}$ & 4.21 & 4.35 & 4.72 & 4.82 & 5.53 & 5.26 & 5.23 \\
\hline
\end{tabular}

Data resources: the yearly statement of $\mathrm{AB}$ InBev and China Brewery Association

According to AB InBev's sales income in Fujian province, we can conclude that the sales income rose from 421 million dollars to 523 million dollars from 2010 to 2016 . It developed in a rising trend overall, but in fact, the real growth took place from 2010 to 2014.It is 2014 that witnessed the zenith of 553 million dollars during the past few years. After 2014, the sales income actually declined and it dropped to 526 million dollars in 2015 , followed by the the further decrease of 3 million dollars in 2016, which should be highly noticed by $\mathrm{AB}$ InBev concerning this decline for two consecutive years.

$\mathrm{AB}$ InBev is experiencing fierce competition in its current various marketing channels. AB InBev is accompanied with the disadvantage of pricing and difficult to compete with low and mid priced domestic beer products in the low-end areas. However, in the areas of high consumption level, AB InBev is a little out-of-date in the product packaging design. Besides, a large number of increasing imported brands push $A B$ InBev in the tense competition. Therefore, further improving marketing channels is the key for $\mathrm{AB}$ InBev to obtain further development in Fujian beer market.

3. The problems of Anheuser-Busch InBev concerning marketing channels 


\section{1 lack of segments in the marketing channels}

In the marketing channels of Anheuser-Busch InBev, the key problem is lacking specific segments. Among the three Anheuser-Busch InBev brands in the Fujian beer market, only Budweiser aims at high-consumption places such as bars and KTVs, except which AB InBev stays the same in other different kinds of channels. The three brands vary in both product prices as well as brand images and thereby the same marketing channel will bring the following disadvantages to $\mathrm{AB}$ InBev.

It increases the distribution cost of marketing channels for $\mathrm{AB}$ InBev. Beer products all need some costs to hit their shelves, including not only specific advertisements but also the charge for retail outlets to put products on the shelves. But in fact, retail terminals can only carry limited marketing resources based on special reasons, in which context AB InBev's overall distribution for plenty of supermarket terminals and dining entertainment terminals requires higher cost.

Secondly, mainstream customers demand varies in different marketing channels. For example,

\subsection{Poor management in the terminal of marketing channels}

It is the terminal sales promoters that matter to achieve effective marketing, in addition to the advertising, the distribution and the quality of products. Especially the beer, as a kind of fast-moving consumer goods, can't always maintain customers' loyalty. Terminal sales promoters will have an vital impact on the marketing through the channels such as catering and supermarket retailing. There are two kinds of terminal sales promoters. One is embodied in the terminal retailer's self-promotion, for example, grocery store keepers actively promote Budweiser for the customers around or restaurateurs focus on sales of Budweiser on the menu or KTVs provide Budweiser acquiescently for consumers and so on. The other is that the special Budweiser terminal sales promoters wear Budweiser advertising uniforms to propagandize the product. But at present, not enough importance is attached to Budweiser terminal sales promoters in the Fujian beer market because expanding market is considered to depends on the brand image, advertising, product quality, along with active choices of the consumers.

\subsection{Untight cooperation among offline channels}

It is a problem that the cooperation of offline channels is not tight enough. In terms of managing marketing channels, $A B$ InBev attaches importance on the management of the dealer rather than the management of real marketing terminal. In August, 2016, the dispute between AB InBev and dealers had a great social impact, indicating that highly regulating of marketing channels was needed because $A B$ InBev asked for more responsibilityfrom dealersthan it undertook. And it is disadvantageous for the $\mathrm{AB}$ InBevs management development of marketing channels in Fujian province. In the AB InBev's short-term marketing channels, the dealer is of great significance because a dealer often directly represents all products' marketing conditions of $\mathrm{AB}$ InBev within a region. With the exclusive marketing operation, any change by dealers, such as altering the brand, working on distributions of other brands, and cooperating with other investors or dealers etc, will have a huge market effect on AB InBev.

\subsection{The inadequate construction of brand image in marketing} channels

$\mathrm{AB}$ InBev attaches great importance to its own products' brand images. After all, as a special product of beer, AB InBev does not taste better than those with a little lower prices. ChinaResources beer, Tsingtao beer and other beer companies all has launched a series of high-end products whose flavor is not inferior to AB InBev's. So AB InBev also affixes significance to strengthening its brand image actively in order to achieve the spiritual added value of the consumer as well as enhance the products' competitiveness. Since $\mathrm{AB}$ InBev entered China, it has actively propagandized its brand image in many different ways. According to the iResearch statistics, in October 2016, AB InBev's advertising cost reached about 29 million yuan as the top among China.

A great amount of AB InBev's brand image construction is not deeply rooted in the specific marketing channels. $A B$ InBev almost just puts up the basic posters, hands out simple openers, and prints lighters etc. Under such circumstances, the value of $A B$ InBev brand image can not be taken full advantage of in Fujian beer market inevitably. Consumers can only recall $A B$ InBev's advertising from the previous relevant advertisements and can not feel the added value of $A B$ InBev's brand spirits in the process of purchasing.
4. Countermeasures and suggestions for $A B$ InBev to improve the beer marketing channels

\subsection{Segment of marketing channels}

On one hand, AB InBev should comb through its current products. For example, even Budweiser has such top products of ultra-high specification as Budweiser-customized products featured by the Rooster Year, starcustomized aluminum cans and master gold label, which are even more expensive than the general imported goods and the red wine or the liquor with the same volume. In addition to the general taste, Sedrin beer also launches sweet and sour lemon soda beer, more suitable for women. The main marketing channels of these different products are certainly different. On the other hand, it is necessary to subdivide the specific marketing channels and comb through different marketing channels in detail. We recommend that $\mathrm{AB}$ InBev conduct a statistical report on all marketing terminals in Fujian province, that is, the sales status of all kinds of products in the specific marketing terminals, and know about those of other beer in the marketing terminals. If a product does not accord with the expected sales status, AB InBev should consider whether to exit the channel and put limited resources into the product promotion with better sales of the channel.

\subsection{Pay attention to terminal promotion.}

Apart from active brand building and advertising promotion, $\mathrm{AB}$ InBev should pay attention to the terminal promotion in any marketing channels to ensure the full grasp of the whole marketing.

Firstly, the terminal businessmen should actively play the role of their promotional value. Especially for various retail terminals, public dining and entertainment, $\mathrm{AB}$ InBev needs to improve the enthusiasm of these businessmen to actively promote the products by stepped promotional strategies as well as shelving agreements to make AB InBev's products placed conspicuously and AB InBev's advertising posters put up more so that businessmen respond more positively to several $A B$ InBev's marketing measures.Secondly, it is necessary to build an official terminal sales team. AB InBev should set up a team of promotional talents from the enterprise point of view and abandon the behaviors of dealers' own selfrecruiting. Through this official marketing team,we should first train them from the perspective of the enterprise and achieve better management with long-term fixed career. And then $A B$ InBev need to play the role of business resources to promote products, such as special Budweiser tasting outlets, brands' promotion and so on.

\subsection{Secure marketing channels in diversified ways}

$\mathrm{AB}$ InBev has its own considerations for the highly control of marketing channels, but the basis of highly control is the stability of the marketing channels. So it is recommended that $\mathrm{AB}$ InBev master the marketing channels from two aspects.For one hand, $\mathrm{AB}$ InBev needs to cooperate with the existing dealers for further stable relationship. AB InBev should establish a good relationship with a number of dealers and avoid all kinds of disputes caused by negligence. In particular, we need pay attention to ensuring the dealers' reasonable interests and only with the dealers' higher allegiance can highly control be achieved because allegiance is the basis of the interests. AB InBev is to first ensure the delightful smooth cooperation and promptly do the turnover work of accounts receivable with the dealers. It is necessary to both encourage dealers to make recommendations as well as attach great importance to products and respect the interests of each dealer as well as regard them as an important partner.

\subsection{Put the brand image construction into the marketing channels}

First, make more efforts for constructing the counter. For different retailing terminal channels, the display cases' size and appearance is of course different. Second, organize offline activities actively. AB InBev can use its own presence to organize some social activities in line with the brand image and beneficial to citizens. Besides actively filming videos related to public welfare, they should also propagandize civilized drinking, healthy drinking and stopping drunk driving as well as alcoholism, in order to expand the influence through posters and local propaganda. It is another good idea to organize small concerts or local scenic tours and so on. $A B$ InBev need expand its influence through a few offline activities.

\section{Conclusion}

Marketing channels are key for $A B$ InBev to develop positively in the Fujian beer market. It can be said that the marketing channels directly determine whether its product quality and good brand image are able to play the role to promote its marketing finally. In this paper, some 
suggestions are brought up for $\mathrm{AB}$ InBev to cope with its disadvantages in the current marketing channels of Fujian beer market. These valuable recommendations can effectively improve the marketing channels for $\mathrm{AB}$ InBev to play a positive role.

References

[1] S.Y.Luo .Study on Channel Conflict Governance Based on Channel Alliance Motivation [D]. Hunan University, 2012, (24)

[2] K.F.Li. On the drug marketing channel system innovation [J]. Economic Research Guide, 2011, (06): 48-51.

[3] Ledi. The analysis of Hubei Jinlongquan beer marketing channels [J]. Contemporary economy, 2015 (23): 100-101.
[4] Y.Shi ,J. Ming. J.Yan Beer Marketing Strategy Research of Tongliao area [J]. border economy and culture, 2015 (5): 33-35.

[5] Y.J.Wang . QD beer network marketing strategy research [D]. China Ocean University, 2015

[6] W.Tang. The research on management strategies of marketing channel terminals in Tongling Tobacco Company [D]. Anhui University, 2014.

[7] J.R.Yang. Research on the Tender Mechanism of Alliance Channel Management [D]Journal of Chongqing Technology and Business University (Social Science Edition) "2009-01. 